\title{
Facility Oncology Registry Data Standards
}

National Cancer Institute

\section{Source}

National Cancer Institute. Facility Oncology Registry Data Standards. NCI Thesaurus.

Code C88367.

A coding manual produced by the Commission on Cancer of the American College of

Surgeons that provides definitions and detailed instructions for coding patient diagnosis, treatment, and outcome. 